\title{
PERFIL DO AGRESSOR DE VIOLÊNCIA SEXUAL CONTRA CRIANÇAS E ADOLESCENTES: CASOS NOTIFICADOS NOS CONSELHOS TUTELARES DE FEIRA DE SANTANA NOS ANOS DE 2014 A 2016
}

\section{Larissa Santana de Jesus ${ }^{1}$; Jamilly de Oliveira Musse ${ }^{2}$; Gabrielly Dias Marques $^{3}$}

\section{Daniela Pereira Portugal Souza ${ }^{4}$}

1. Bolsista PIBIC/CNPq, Graduando em Psicologia, Universidade Estadual de Feira de Santana, e-mail: larissa.santana017@gmail.com

2. Orientador, Departamento de Saúde, Universidade Estadual de Feira de Santana, e-mail: musse_jo@ hotmail.com 3. Participante do Núcleo de Estudos e Pesquisas na Infância e Adolescência, Departamento de Saúde, Universidade Estadual de Feira de Santana, e-mail: gabynnepa@ hotmail.com

4. Graduanda em Psicologia, Universidade Estadual de Feira de Santana, e-mail: danielapportugal@ gmail.com

PALAVRAS-CHAVE: agressor, violência sexual, crianças e adolescentes.

\section{INTRODUÇÃO}

A existência da violência pode ser visualizada desde os primórdios da humanidade a nível mundial, ou seja, não trata-se de um acontecimento atual, mas histórico e complexo.Consequentemente, apesar de ser uma temática pautada em grandes discussões, continua sendo um grande desafio para a sociedade contemporânea (LEVISKY, 2010).

Ainda referente à dinâmica da violência, apresenta-se nas relações de múltiplas maneiras, pois a sua ocorrência é relacional e multicausal, considerando a complexidade das interações humanas (MINAYO, 2006). Dessa forma, tal fenômeno social pode acarretar diversas consequências biopsicossociais para a saúde dos indivíduos.

No que concerne a violência, diz respeito a toda qualquer ação (com ou sem o uso da força física) que defronte ao arbítrio do indivíduo a, geralmente, tem como característica o uso de coerção, opressão e intimidação, as quais transgridem os valores convencionados pela sociedade de direitos (TEIXEIRA-FILHO et al., 2013; COSTA, 2012).

No contexto brasileiro, os índices de violação dos direitos contra crianças e adolescentes são alarmantes. Consequentemente é provável concluir que esta população é vulnerável a diversas formas de violência, sendo as mais recorrentes: negligência, o trabalho precoce e a violência sexual (FONSECA et al., 2013).

No que tange a defesa de direitos desta população, o Estatuto da criança e adolescente ECA estabelece que o Conselho Tutelar (CT) é o órgão que deve executar medidas para a proteção e garantia dos direitos na infância e adolescência, o CT compõe parte do Sistema de Garantia de Direitos, caracterizado na Resolução 113/2006 do Conselho Nacional dos Direitos da Criança e do Adolescente (CONANDA).

A violência sexual apresenta-se em duas formas distintas: intrafamiliar, quando acontece no contexto familiar, onde o agressor possui um vínculo parental com a vítima; já a extrafamiliar, trata-se de uma ocorrência fora do âmbito familiar, porém, via de regra, cometida por pessoas de confiança da vítima e de sua família (COSTA, 2012). A despeito disso, existem poucos estudos concernentes o perfil do perpetrador da violência sexual, o que corrobora com o cenário atual em termo de investimento em políticas públicas com o intuito de prevenir, minimizar ou erradicar tal violação.

\section{MATERIAL E MÉTODOS OU METODOLOGIA}

Estudo epidemiológico descritivo acerca do perfil do agressor de violência sexual, com base em dados secundários, produzidos a partir das notificações de violência sexual efetuadas nos Conselhos Tutelares (I, II, III e IV) da cidade de Feira de Santana, nos anos de 2014 a 2016. 
Quanto à coleta, os dados foram coletados dos prontuários de atendimentos de crianças e adolescentes na faixa de 0 a 18 anos, vítimas de violência sexual, a partir do uso de um formulário estruturado contendo as seguintes variáveis: local onde ocorreu a violência; e o tipo de violência sexual (sedução, estupro, incesto, pedofilia, pornografia, tráfico, outras); vínculo do agressor com a vítima (pai, mãe, padrasto, madrasta, irmãos, tios, avós, outros); sexo; idade; grau de instrução; ocupação; grau de consciência; tipo de intimidação e se houve vitimização por mais de um agressor. No tocante ao processamento dos dados, foi realizado através do programa estatístico Social Package for the Social Sciences - SPSS, versão 17.0 for Windows.

Esta pesquisa foi realizada por meio do vinculo com o projeto de pesquisa intitulado "Rede de proteção e prevenção da violência e garantia dos direitos humanos: integração Universidade e Sistemas de Segurança Pública, Atendimento e Defesa da infância, adolescência e juventude", aprovado pelo Comitê de Ética da UEFS, sob protocolo de nº 143/10 (CAAE - 0118.0.059.000-10).

\section{RESULTADOS E/OU DISCUSSÃO}

Conforme os registros dos Conselhos Tutelares I, II, II e IV, nos anos de 2014, 2015 e 2016 foram notificados o total de 193 casos de violência sexual contra crianças e adolescentes em Feira de Santana. No que tange ao triênio (2014-2016) já citado, a quantidade de notificações por ano foram 71, 31 e 91 casos respectivamente totalizando 193 registros. Levando em consideração o tipo de violência sexual, percebe-se que $91,2 \%$ das violações foram caracterizadas enquanto abuso sexual e $8,8 \%$ de exploração sexual.

Nos achados deste estudo, quanto ao perfil do agressor (Tabela 02), verifica-se que o vínculo mais predominante do perpetrador com a vítima é o de conhecidos de familiares ou da vítima representado por $32,1 \%$, mas aponta também que 5,2\% dos perpetradores eram desconhecidos. Entretanto, no que se refere ao contexto intrafamiliar, houve hegemonia de $15 \%$ das agressões praticadas pelos padrastos da vítima, em seguida, $14 \%$ destas cometidas por pais, $5,2 \%$ dos casos foram perpetrados pelas mães e 17,6\% por outros membros da família (primos $(5,7 \%)$; Tios $(8,3 \%)$ / Avós $(1,5 \%)$ e irmão $(2,1 \%)$.

Ao falar de violência intrafamiliar, também corroboram com a pesquisa de Teixeira-Filho et al (2013), onde há um destaque para a figura do pai e do padrasto como principais perpetradores dentro do âmbito familiar. Contudo, a agressão sexual intrafamiliar denota a perpetuação de um ciclo de violência duradoura que dificulta o rompimento deste e favorece a frequência de efeitos danosos para o sujeito, no âmbito psicológico, social e afim (COSTA; ROCHA; CAVALCANTE, 2018).

$\mathrm{O}$ fato do agressor, geralmente, está inserido no contexto familiar ou no meio de confiança da vítima, tem influência direta nas subnotificações dos casos, a repressão, a culpa e a vergonha atuam de tal forma que a deixa intimidada. Além disso, há a existência das ameaças aliadas ao receio de não acreditarem em sua versão e o medo de ser punido são fatores que dificultam a interrupção da violência (FUKUMOTO, CORVINO, NETO, 2011).

Concernente as características sociodemográficas dos agressores, conforme a amostra analisada, estes eram predominantemente do sexo masculino $(77,2 \%)$ restando $10,4 \%$ feminino. Além disso, referente à faixa etária identificou-se que, dentre os 193 casos registrados, 5,2\% dos perpetradores tinham idade de 12 a 18 anos, $3,1 \%$ de 0 a 11 anos e, por último, 1,5\% dos vitimizadores apresentavam idade acima de 60 anos, contudo a quantidade mais expressiva acerca desta variável foi ignorada $(76,2 \%)$. O contexto predominante da agressão é a casa da vítima $(50,3 \%)$. No entanto, a maioria dos agressores eram conhecidos da família ou da vítima $(32,1 \%)$.

Acerca do grau de instrução dos perpetradores, a 2,6\% destes cursaram o ensino fundamental incompleto, superior incompleto $(0,5 \%)$, não alfabetizado $(0,5 \%)$ e $91,3 \%$ destes dados foram ignorados pelos conselheiros. Tangente a ocupação dos agressores a pesquisa 
demonstra que pertenciam às seguintes profissões: estudantes $(5,2 \%)$, autônomo $(0,5 \%)$, cobrador $(0,5 \%)$, motoboy $(0,5 \%)$, motorista de transporte escolar $(0,5 \%)$, comerciante $(0,5 \%)$, servente $(0,5 \%)$.Considerando os dados citados, o fato dos agressores estarem ativos no mercado de trabalho é apresentado também na pesquisa de Santos et al (2015).

Assim, quanto à caracterização do agressor sexual desta pesquisa, coaduna, em certa medida, com o estudo desenvolvido por Costa; Rocha; Cavalcante (2018), onde 97\% dos agressores eram do sexo masculino e, predominantemente, com baixa escolaridade. No tocante ao grau de consciência do agressor, a maioria deles estava em estado normal $(48,3 \%)$ seguido de 4,8\% dos agressores estavam alcoolizados no momento da agressão, $7 \%$ fizeram uso de outras drogas e houve um caso específico cujo sujeito é acometido de transtornos mentais $(0,5 \%)$.

Neste estudo constatou-se que, dentre as situações registradas prevaleceu a não vitimização por mais de um agressor (87\%). Quanto ao tipo de intimidação utilizada para a manutenção da violência sexual, há a preeminência de $22,8 \%$ do uso da força física, o que diverge dos dados do estudo de Santos et al (2015), na mesma cidade, que constatou que principal tipo de intimidação, é sedução e ameaça.

Tabela 1: Perfil do agressor de violência sexual segundo dados dos Conselhos Tutelares, no período de 2014 a 2016. Feira de Santana, BA, Brasil.

\begin{tabular}{|c|c|c|}
\hline \multirow{2}{*}{ Características do Agressor } & \multicolumn{2}{|c|}{ Total } \\
\hline & $\mathbf{N}$ & $\%$ \\
\hline \multicolumn{3}{|c|}{ Vinculo do agressor com a vítima $(n=193)$} \\
\hline Pai & 27 & 14,0 \\
\hline Padrasto & 30 & $\mathbf{1 5 , 5}$ \\
\hline Mãe & 10 & $\mathbf{5 , 2}$ \\
\hline Outros familiares $^{1}$ & 34 & 17,6 \\
\hline Conhecidos da família ou da vítima & 63 & 32,1 \\
\hline Desconhecidos & 10 & 5,2 \\
\hline Ignorado & 19 & 10,4 \\
\hline \multicolumn{3}{|l|}{ Sexo do agressor $(n=193)$} \\
\hline Masculino & 149 & $\mathbf{7 7 , 2}$ \\
\hline Feminino & 20 & 10,4 \\
\hline Ignorado & 24 & 12,4 \\
\hline \multicolumn{3}{|l|}{ Faixa etária do agressor (n=193) } \\
\hline $0-11$ & 06 & 3,1 \\
\hline $12-18$ & 10 & 5,2 \\
\hline $19-59$ & 27 & 14 \\
\hline $60+$ & 03 & 1,5 \\
\hline Ignorado & 147 & $\mathbf{7 6 , 2}$ \\
\hline \multicolumn{3}{|l|}{ Grau de Instrução (n=193) } \\
\hline Não alfabetizado & 01 & 0,5 \\
\hline Fundamental incompleto & 05 & 2,6 \\
\hline Superior incompleto & 01 & 0,5 \\
\hline Ignorado & 186 & 96,4 \\
\hline \multicolumn{3}{|l|}{ Ocupação do agressor $(n=193)$} \\
\hline Autônomo & 1 & 0,5 \\
\hline Cobrador & 1 & 0,5 \\
\hline Comerciante & 1 & 0,5 \\
\hline Desempregado & 1 & 0,5 \\
\hline Estudante & 10 & 5,2 \\
\hline Moto boy & 1 & 0,5 \\
\hline Motorista de transporte escolar & 1 & 0,5 \\
\hline Servente & 1 & 0,5 \\
\hline Ignorado & 176 & 91,3 \\
\hline
\end{tabular}




\begin{tabular}{|c|c|c|}
\hline \multicolumn{3}{|c|}{ Grau de Consciência do agressor (n=197) } \\
\hline Normal & 110 & 48,3 \\
\hline Alcoolizado & 11 & 4,8 \\
\hline Drogado & 16 & $\mathbf{7 , 0}$ \\
\hline Outro $^{2}$ & 01 & 14,0 \\
\hline Ignorado & 59 & $\mathbf{2 5 , 9}$ \\
\hline \multicolumn{3}{|c|}{ Houve vitimização por mais de um agressor $(n=193)$} \\
\hline Sim & 20 & 10,4 \\
\hline Não & 168 & 87,0 \\
\hline Ignorado & 05 & 2,6 \\
\hline \multicolumn{3}{|l|}{ Tipos de Intimidação (n=82) } \\
\hline Força física & 44 & 22,8 \\
\hline Ameaça & 36 & 18,6 \\
\hline Arma fogo/ ou Arma branca & 02 & 1,0 \\
\hline
\end{tabular}

Quanto às formas de manifestação de contato, o estupro sem penetração (cariciais sexuais e atos libidinosos) foi o mais expressivo $(n=69)$ e, na sequência, o estupro com penetração $(\mathrm{n}=39)$. Com relação ao perfil do agressor das violações supracitadas, $7,7 \%$ dos pais perpetradores cometeram estupros com penetração, no entanto, 20,6\% dos casos foram perpetrados por padrastos, $5,1 \%$ por irmãos, $10,3 \%$ por tios, $5,1 \%$ por vizinhos, $51,1 \%$ por outros. Já quanto ao estupro sem penetração, das 69 ocorrências, 27,6\% das agressões são praticadas por pais, $2,9 \%$ perpetradas por mães, $24,7 \%$ por padrastos, $1,5 \%$ por irmãos das vítimas, $11,6 \%$ dos tios, corresponde a $4,3 \%$ das agressões praticadas por avós, 4,3\% por vizinhos e, por fim, $23,1 \%$ realizada pelos outros.

Vale ressaltar que, tendo em vista o total geral, observa-se que as agressões provenientes do pai e o padrasto são semelhantes no que refere-se à mesma quantidade de perpetração $(14,4 \%)$, entretanto apresenta algumas diferenças que são patentes ao observar que, ao trata-se de estupro,com penetração o principal violador é o padrasto $(20,6)$, já com relação ao estupro sem penetração, o pai ganha destaque $(27,6 \%)$.

Tabela 2: Distribuição dos casos de violência sexual e o perfil do agressor segundo dados dos Conselhos Tutelares, no período de 2014 a 2016. Feira de Santana, BA, Brasil

${ }^{1}$ Adolescente $(n=1)$, adolescente conhecido $(n=2)$, amigo da mãe $(n-1)$, colega da escola $(n=4)$, conhecido da vitima $(n=20)$, colegas da escola (n-1), criança conhecida ( $\mathrm{n}-1)$, cunhado da vítima $(\mathrm{n}=3)$, desconhecido $(\mathrm{n}=10)$, dono da creche $(\mathrm{n}=1)$, ex companheiro da mãe $(n=1)$, namorado da vítima $(n=10)$, prima $(n=2)$ e primo $(n=9)$

\begin{tabular}{|c|c|c|c|c|c|c|c|c|c|c|c|c|c|c|c|c|c|c|c|c|}
\hline \multirow{2}{*}{$\begin{array}{c}\begin{array}{c}\text { Tipos de } \\
\text { violência }\end{array} \\
\text { Agressores }\end{array}$} & \multicolumn{2}{|c|}{ Estupro } & \multicolumn{2}{|c|}{$\begin{array}{c}\text { Estupro } \\
\text { s/penetraçã }\end{array}$} & \multicolumn{2}{|c|}{ Assédio } & \multicolumn{2}{|c|}{ Exibicionismo } & \multicolumn{2}{|c|}{ Voyeurismo } & \multicolumn{2}{|c|}{ Sedução } & \multicolumn{2}{|c|}{ Pedofilia } & \multicolumn{2}{|c|}{ Pornografia } & \multicolumn{2}{|c|}{ Exploração } & \multicolumn{2}{|c|}{ Total } \\
\hline & $\mathbf{N}$ & $\%$ & $\mathbf{N}$ & $\%$ & $\mathbf{N}$ & $\%$ & $\mathbf{N}$ & $\%$ & $\mathbf{N}$ & $\%$ & $\mathbf{N}$ & $\%$ & $\mathbf{N}$ & $\%$ & $\mathbf{N}$ & $\%$ & $\mathbf{N}$ & $\%$ & $\mathbf{N}$ & $\%$ \\
\hline Pai & 3 & 7,7 & 19 & 27,6 & - & - & - & - & - & - & 2 & 25 & - & - & - & - & 5 & 31,3 & 29 & 19,4 \\
\hline Mãe & - & - & 2 & 2,9 & 4 & 40 & 1 & 50 & - & - & - & - & - & - & - & - & 3 & 18,8 & 10 & 6,8 \\
\hline Padrasto & 8 & 20,6 & 17 & 24,7 & 1 & 10 & - & - & 1 & 100 & 1 & 12,5 & - & - & - & - & 1 & 6,2 & 29 & 19,4 \\
\hline Irmãos & 2 & 5,1 & 1 & 1,5 & - & - & - & - & - & - & - & - & - & - & - & - & 1 & 6,2 & 4 & 2,7 \\
\hline Tios & 4 & 10,3 & 8 & 11,6 & - & - & - & - & - & - & 2 & 25 & - & - & - & - & - & - & 14 & 4 \\
\hline Avós & - & - & 3 & 4,3 & - & - & - & - & - & - & - & - & - & - & - & - & - & - & 3 & 2 \\
\hline Vizinhos & 2 & 5,1 & 3 & 4,3 & 1 & 10 & - & - & - & - & 2 & 25 & - & - & 1 & 100 & - & - & 9 & 6 \\
\hline Outros ${ }^{1}$ & 20 & 51,2 & 16 & 23,1 & 4 & 40 & 1 & 50 & - & - & 1 & 12,5 & 3 & 100 & - & - & 6 & 37,5 & 51 & 34,3 \\
\hline Total & 39 & 100 & 69 & 100 & 10 & 100 & 2 & 100 & 1 & 100 & 8 & 100 & 3 & 100 & 1 & 100 & 16 & 100 & 149 & 100 \\
\hline
\end{tabular}




\section{CONSIDERAÇÕES FINAIS}

No período estudado, foram notificados 193 casos, a predominância de agressores do sexo masculino (77,2\%); cerca de 5,2\% dos perpetradores adolescentes (12 a 18 anos); com baixa escolaridade $(2,6 \%)$; membros da família $(59,7 \%)$; vizinhos e conhecidos(32,8\%); cujo o grau de consciência do agressor normal foi considerado normal, ou seja, sem uso de substâncias psicoativas (48,3\%); Em 87\% dos casos não houve vitimização por mais de um agressor e o tipo de intimidação mais utilizado foi a força física $(22,8 \%)$.

Tendo em vista os dados supracitados, o perfil de perpetração de violência sexual contra crianças e adolescentes indicam que a violência intrafamiliar é frequente, sendo que fato do agressor, geralmente, está inserido no contexto familiar ou no ciclo de confiança da vítima, isto tem influência direta nas subnotificações dos casos, pois a realidade é, provavelmente, mais que o dobro dos casos registrados no CT. Além disso, há a existência das ameaças aliadas ao receio de não acreditarem em sua versão e o medo de ser punido são fatores que dificultam a interrupção da violência.

Enfim, existem poucos estudos sobre agressor sexual, entretanto, é muito importante que este perfil seja conhecido para a criação de políticas públicas a fim de minimizar esse grande problema social. Para tanto, se faz necessário uma avanço que perpassa desde o processo de notificação da violência sexual a subsídios de políticas e programas de prevenção e enfrentamento social contra a violência sexual, desenvolvendo ações que sensibilize a família, escola, enfim, toda sociedade.

\section{REFERÊNCIAS}

BRASIL. Estatuto da Criança e do Adolescente, Câmera dos Deputados, Lei no 8.069, de 13 de julho de 1990. DOU de 16/07/1990 - ECA. Brasília, DF

MINAYO, M. C. S. Violência e saúde. SciELO-Editora FIOCRUZ, 2006.

LEVISKY, D. L. Uma gota de esperança. ALMEIDA, M.G. B. A violência na sociedade contemporânea. Porto Alegre: EDIPUCRS, p. 06-12, 2010.

FUKUMOTO, A. E. C. G.; CORVINO, J. M.; NETO, J. O. Perfil dos agressores e das crianças e adolescentes vítimas de violência sexual. Rev. Ciênc. Ext. v.7, n. 2, p. 81, 2011.

COSTA, M. C. O. Diga não à violência sexual contra crianças e adolescentes no seu município. Feira de Santana - BA: UEFS, 2012.

FONSECA, F. F. et al. As vulnerabilidades na infância e adolescência e as políticas públicas brasileiras de intervenção. Revista Paulista de Pediatria, v. 31, n. 2, p. 258-264, 2013.

TEIXEIRA-FILHO, F.S. et al. Tipos e consequências da violência sexual sofrida por estudantes do interior paulista na infância e/ou adolescência. Rev. Psicologia \& Sociedade, v. 25, n. 1, p. 90-102, 2013.

SANTOS, C. A.; COSTA, M.C.O.; AMARAL, M. T. R.; SOBRINHO, C. L. N.; MUSSE, J. O.; COSTA, A. M. Agressor sexual de crianças e adolescentes: análise de situações relacionadas à violação e vítimas.

Adolescência e Saúde, v. 12, n. 3, p. 7-20, 2015.

COSTA, L. P.; ROCHA, C. J. B.; CAVALCANTE, L. I. C. Características biopsicossociais entre acusados de agressão sexual contra crianças/adolescentes em contextos intra e extrafamiliar. Trends in Psychology, v. 26, n. 1, p. 283-295, 2018. 